\title{
Ketinggian Pangkas Berat dan Pupuk Organik terhadap Biomassa dan Flavonoid Daun Kemuning pada Panen Pertama dan Kedua
}

\section{The Effect of Heavy Pruning and Organic Fertilizer to Biomass and Flavonoid Production Orange Jessmine Leaves at the First and Second Harvest}

\author{
Gusti Eman Ayu Sasmita Jati ${ }^{1}$, Sandra Arifin Aziz ${ }^{2 *}$, dan Maya Melati ${ }^{2}$
}

Diterima 22 Mei 2018/Disetujui 02 April 2019

\begin{abstract}
Harvesting of orange jessamine (Murraya paniculata (L.) Jack.) by pruning at the same height continously causes the decreasing of production. It is lack of previous report on the heavy pruning application in orange jessamine. The study aimed to determine the appropriate height of heavy pruning and level of fertilizers application in order to maintain stable yield production of orange jessamine leaves. The study was conducted from July 2015 to July 2016 at the Organic Experimental Station of Bogor Agricultural University in Cikarawang Bogor. The experiment used a randomized block design with two factors and four replications. The first factor was pruning height consisted of 45, 60 and $75 \mathrm{~cm}$ above the soil surface. Height of $75 \mathrm{~cm}$ was designed as control. The second factor was combination of chicken manure (CM) and rice-husk ash (RA), i.e., without fertilizer (control), 7 $\mathrm{kg} C M+3 \mathrm{~kg} R A$, and $14 \mathrm{~kg} C M+6 \mathrm{~kg} R A$ per plant. The harvest was done two times with four month intervals. The results showed that the pruning height of $60 \mathrm{~cm}$ above the soil surface was the best heavy pruning for growth, production and the total content of flavonoids of orange jessamine plants aged 45-57 month after planting after 4-6 harvests, while fertilization treatments did not produce significantly different results.
\end{abstract}

Keywords: chicken manure, pigment content, pruning height, rice-husk ash

\begin{abstract}
ABSTRAK
Pemanenan kemuning (Murraya paniculata (L.) Jack.), dengan cara pangkas di ketinggian yang sama terus-menerus dapat menyebabkan penurunan produksi. Penerapan pangkas berat terhadap tanaman kemuning belum pernah dilaporkan sebelumnya. Penelitian ini bertujuan untuk menentukan ketinggian pangkas dan dosis pupuk yang sesuai untuk mempertahankan atau meningkatkan produksi daun kemuning dan flavonoid. Penelitian dilakukan dari bulan Juli 2015 sampai Juli 2016. Percobaan dilakukan di Kebun Percobaan Organik Institut Pertanian Bogor di Cikarawang, Bogor. Percobaan menggunakan rancangan acak kelompok dengan dua faktor dan empat ulangan. Faktor pertama adalah tinggi pemangkasan yang terdiri atas 45, 60 dan $75 \mathrm{~cm}$ di atas permukaan tanah. Ketinggian $75 \mathrm{~cm}$ didesain sebagai kontrol. Faktor kedua adalah kombinasi dosis pupuk kandang ayam (PA) dan abu sekam (AS), yaitu: tanpa pupuk (kontrol), $7 \mathrm{~kg}$ PA $+3 \mathrm{~kg}$ AS, dan $14 \mathrm{~kg}$ PA $+6 \mathrm{~kg}$ AS per tanaman per tahun. Panen dilakukan dua kali dengan interval empat bulan. Hasil penelitian menunjukkan bahwa ketinggian pangkas $60 \mathrm{~cm}$ di atas permukaan tanah merupakan pemangkasan berat terbaik untuk pertumbuhan, produksi, dan produksi total flavonoid daun tanaman kemuning yang berusia 45-57 bulan setelah tanam (BST) setelah 4-6 kali panen, sementara perlakuan pemupukan tidak memberikan hasil yang berbeda nyata.
\end{abstract}

Kata kunci: abu sekam, kandungan pigmen, pupuk kandang ayam, tinggi pangkasan

\footnotetext{
${ }^{1}$ Mahasiswa Pascasarjana, Departemen Agronomi dan Hortikultura, Fakultas Pertanian, Institut Pertanian Bogor J1. Meranti Kampus IPB Darmaga, Bogor 16680

${ }^{2}$ Departemen Agronomi dan Hortikultura, Fakultas Pertanian, Institut Pertanian Bogor

Jl. Meranti Kampus IPB Darmaga, Bogor 16680

E-mail : sandra.a.aziz@gmail.com (*Penulis korespondensi)
} 


\section{PENDAHULUAN}

Kemuning (Murraya paniculata (L.) Jack.) merupakan tanaman asli Indonesia yang berpotensi tinggi untuk dikembangkan. Potensi tersebut dapat dilihat dari kemudahannya untuk dibudidayakan, bagian tanaman yang hampir seluruhnya dapat dimanfaatkan $(\mathrm{Ng}$ et al., 2012), dan efek farmakologi serta kandungan senyawa bioaktifnya. Kemuning dapat tumbuh di berbagai jenis tanah dan tahan kekeringan, serta memiliki toleransi terhadap naungan (Mattjik, 2010). Kemuning berpotensi farmakologi sebagai penurun kolesterol, antihiperglikemia, antioksidan, suplemen makanan anti-diabetes, obat disentri, penyedap, kosmetik analgesik, antibakteri, dan agen antiinflammatory ( $\mathrm{Ng}$ et al., 2012). Kandungan senyawa bioaktif daun kemuning berupa, alkaloid, flavonoid, steroid, saponin, dan tanin (Syahadat dan Aziz, 2012). Flavonoid sebagai antioksidan diisolasi dari seperti daun, bunga, dan bagian korteks tanaman kemuning (Kardono et al., 2003).

Pemanenan daun kemuning dilakukan dengan cara pangkas panen daun beserta rantingnya pada ketinggian $75 \mathrm{~cm}$ dari permukaan tanah (Karimuna, 2015; Taufika, 2016). Dampak pemangkasan yang terusmenerus pada tanaman kemuning perlu dipelajari, sebab menurut PPTK (2006), tanaman teh yang terus-menerus dipangkas di ketinggian yang sama akan menurunkan produktivitas tanaman. Kondisi tanaman kemuning pada penelitian ini sudah tidak baik, karena daun hanya tumbuh di bagian tajuk atas. Hal tersebut dapat dihindari dengan cara memangkas di bawah posisi pangkas biasanya dengan ketinggian yang cukup rendah untuk memunculkan tunas-tunas baru yang lebih baik, cepat, dan banyak. Pangkasan berat dapat merangsang pertumbuhan vegetatif tanaman (Zulkarnain, 2009). Spesies yang berbeda dapat memiliki respon yang berbeda saat dipangkas dengan ketinggian pangkas tertentu sehingga ketinggian pangkasan berat harus dipertimbangkan agar tidak terlalu rendah. Jika dipangkas terlalu rendah maka produksi daun akan lambat. Pemangkasan dapat mempercepat laju fotosintesis karena sinar matahari dapat masuk hingga bagian bawah tajuk. Cahaya yang tinggi menyebabkan stomata tetap terbuka jika air tercukupi bagi tanaman sehingga kadar $\mathrm{CO}_{2}$ meningkat dan menghasilkan laju fotosintesis menjadi tinggi (Maurin dan Des Rochers, 2013; Lisboa et al., 2014). Pemangkasan akan mempengaruhi proses fisiologis tanaman sehingga dapat mengubah metabolisme sekundernya. Tinggi pangkasan dapat mempengaruhi kandungan quersetin pada kulit buah berri cv. Blaufränkisch (Vitis vinifera L.) (Beslic et al., 2010).

Pemupukan dapat menambah hara pada tanaman teh yang dipangkas sehingga bahan makanan tercukupi untuk memproduksi energi dan membangun jaringan untuk penutupan luka dan pertumbuhan tanaman teh yang dipangkas (PPTK, 2006). Pemupukan pada tanaman obat dianjurkan untuk menggunakan pupuk organik. Penggunaan pupuk kandang ayam, guano, dan abu sekam sebagai penambah unsur NPK tanah dapat dipertimbangkan untuk meningkatkan produksi tanaman (Hayanti et al., 2014) sekaligus meningkatkan kandungan senyawa bioaktif dalam daun kemuning (Syahadat dan Aziz, 2012). Dosis pupuk yang sesuai untuk tanaman kemuning perlu dicari agar kebutuhan tanaman pasca pemangkasan dapat terpenuhi dan kesuburan tanah dapat terjaga.

Penelitian ini dimaksudkan untuk melengkapi informasi dalam pembuatan Standard Operation Procedure (SOP) budidaya kemuning yang belum tersusun. Pengetahuan mengenai teknik terbaik dalam pangkas berat untuk pemeliharaan dan pemanenan kemuning yang disertai dengan perlakuan pemupukan setelah pangkas serta interaksi antara pangkas berat dan pemupukan harapannya dapat membentuk sistem budidaya kemuning yang dapat menghasilkan produksi biomassa tinggi dengan kandungan bahan bioaktif yang sesuai standar, stabil, dan berkelanjutan.

\section{BAHAN DAN METODE}

Penelitian dilaksanakan dari bulan Juli 2015 sampai Juli 2016 di Kebun Percobaan Organik IPB di Cikarawang, Dramaga, Bogor, Jawa Barat $\left(6^{0} 30^{\prime}-6^{0} 45^{\prime}\right.$ LS dan $106^{0} 30^{\prime}-106^{\circ} 45^{\prime}$ BT). Jenis tanah pada lahan penelitian adalah Latosol yang berada pada ketinggian tempat 250 meter di atas permukaan laut (mdpl). Data iklim dari Stasiun Klimatologi Darmaga Bogor terdapat pada Gambar 1. Curah hujan terlihat sangat rendah pada awal penelitian, sangat tinggi pada pertengahan penelitian, dan mulai 
turun tapi masih tergolong tinggi pada akhir penelitian. Kelembaban terlihat mengikuti pola curah hujan. Temperatur udara cenderung stabil pada kisaran $26{ }^{\circ} \mathrm{C}$. Intensitas cahaya berada pada kisaran 250-369.92 $\mathrm{Cal} \mathrm{cm}^{-2}$.

Bahan tanaman yang digunakan adalah kemuning berumur 45 bulan setelah tanam (BST) yang telah ditumbuhkan pada jarak tanam $1 \mathrm{~m} \mathrm{x} 1 \mathrm{~m}$ dan merupakan tanaman hasil penelitian sebelumnya dari tahun 2013 hingga 2015 (Utami, 2015; Karimuna, 2015; Taufika, 2016).

Percobaan menggunakan rancangan acak kelompok (RAK) dua faktor yaitu, ketinggian pangkasan berat sebagai faktor pertama: 75 (pangkas panen atau kontrol), 60, dan, $45 \mathrm{~cm}$ dari permukaan tanah. Pangkas berat dilakukan dengan cara memangkas sesuai dengan ketinggian perlakuan dan menyisakan daun, ranting, serta cabang tanaman di bawah tinggi perlakuan agar tetap tumbuh. Sebagai faktor kedua adalah dosis pemupukan setelah panen terdiri atas 3 kombinasi dosis pupuk kandang ayam (PA) dan abu sekam (AS), yaitu tanpa pupuk (kontrol), $7 \mathrm{~kg}$ PA $+3 \mathrm{~kg}$ AS, dan $14 \mathrm{~kg}$ PA $+6 \mathrm{~kg}$ per tanaman per tahun. Setiap perlakuan terdiri atas 2 tanaman dan diulang 4 kali, sehingga diperoleh 72 tanaman.

Pada saat tanaman berusia 45 BST dilakukan pemerataan tinggi tanaman pada ketinggian $75 \mathrm{~cm}$ dari permukaan tanah dengan pemberian pupuk guano $0.42 \mathrm{~kg}$ per tanaman sebagai pupuk dasar seminggu sebelum perlakuan diberikan.
Aplikasi pemupukan sesuai dosis perlakuan dilakukan dengan membuat alur yang mengelilingi tanaman dengan jarak $20 \mathrm{~cm}$ dari batang tanaman dan ditutup dengan tanah. Panen dilakukan dengan cara pangkas sesuai perlakuan sebanyak 2 kali (49 dan 53 BST) dengan interval 4 bulan. Pemupukan diberikan setiap selesai panen, sehingga total masingmasing dosis aplikasi pupuk merupakan dosis per tahun.

Pengamatan yang dilakukan adalah karakter pertumbuhan berupa diameter tajuk, tinggi tanaman, dan jumlah daun pada cabang contoh dilakukan setiap bulan setelah panen pertama (50, 51, dan 52 BST) dan kedua (54, 55, dan 56 BST), sementara jumlah tunas pada cabang contoh diamati pada 1 dan 3 bulan setelah panen pertama (50 dan 52 BST) dan kedua (54 dan 56 BST). Komponen produksi kemuning berupa bobot basah dan bobot kering daun serta bobot basah batang (ranting, cabang, dan batang) dilakukan pada 49 dan 53 BST di Laboratorium Pascapanen, Departemen Agronomi dan Hortikultura, IPB. Pengamatan komponen kandungan fitokimia meliputi kadar pigmen produksi total flavonoid. Pengamtan kadar pigmen (klorofil a, klorofil $\mathrm{b}$, karotenoid, dan antosianin) dilakukan di Laboratorium Pascapanen IPB, pada 49 dan 53 BST dengan metode analisis Sims dan Gamon (2002). Daun segar kemuning dihaluskan, ditambah aceton tris $2 \mathrm{ml}(85: 15(\%))$, dan disentrifuse (14000 rpm selama 10 menit). Hasil supernatant $(1 \mathrm{ml})$ ditambah aceton tris $3 \mathrm{ml}$ dan dicampur rata.

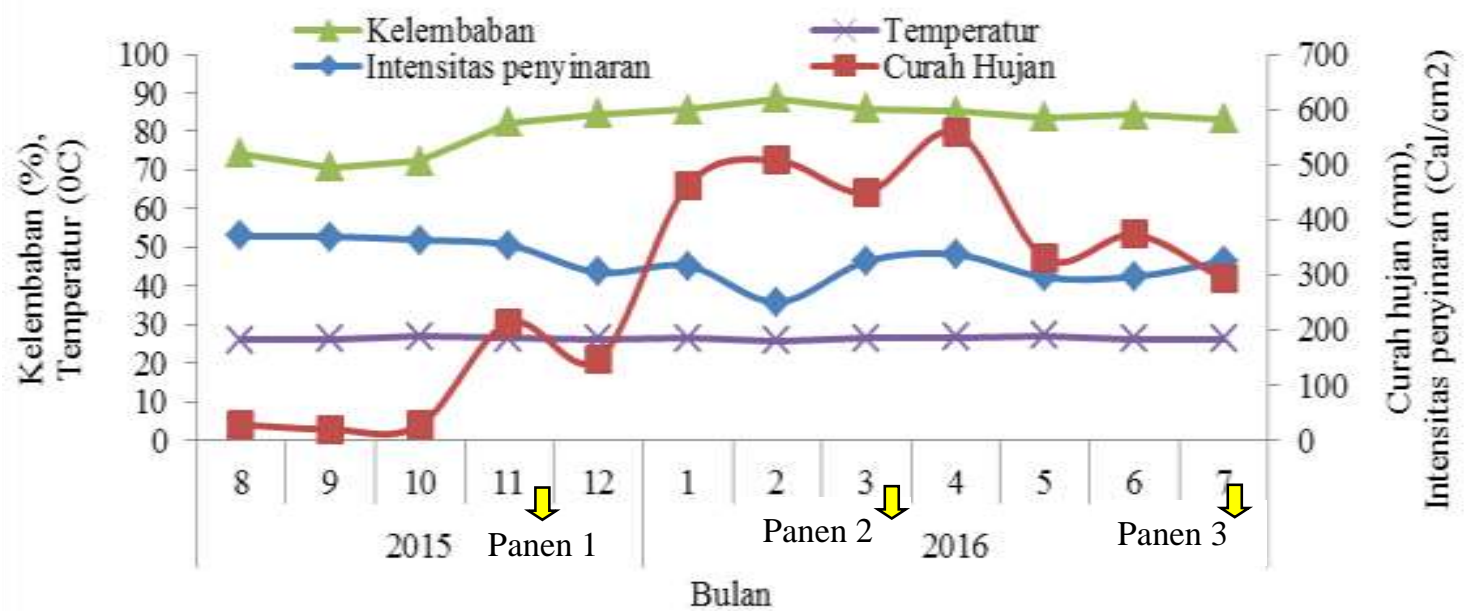

Gambar 1. Kondisi iklim wilayah Dramaga Bogor bulan Agustus 2015 - Juli 2016 
Absorbansi campuran diukur pada panjang gelombang 663, 647, dan $537 \mathrm{~nm}$, diukur dengan Shimadzu UV-1201 UV-VIS spectrophotometer. Hasilnya dinyatakan sebagai milligram per gram bobot basah ( $\mathrm{mg} \mathrm{g}$ $\left.{ }^{1} \mathrm{BB}\right)$. Produksi total flavonoid didapat dari perhitungan bobot kering daun $\left(\mathrm{g} \mathrm{tan}^{-1}\right)$ dikali kadar total flavonoid daun (mg $\mathrm{g}^{-1} \mathrm{BK}$ ). Pengamatan kadar total flavonoid dilaksanakan di Laboratorium Pusat Studi Biofarmaka, IPB hanya pada panen pertama (49 BST) dengan metode ekstrak monograf BPOM (2004). Ekstrak daun kemuning yang telah dikeringovenkan pada suhu $60{ }^{\circ} \mathrm{C}$ selama 3 hari sebanyak $200 \mathrm{mg}$ ditambahkan dengan $1 \mathrm{ml}$ larutan heksametilentetramin $0.5 \% \mathrm{~b} / \mathrm{v}, 20 \mathrm{ml}$ aseton, dan $2 \mathrm{ml}$ larutan HCL 25\%, kemudian dihidrolisis dengan cara direfluks selama 30 menit. Campuran disaring menggunakan kapas dan residunya direfluks kembali dengan $20 \mathrm{ml}$ aseton selama 30 menit, disaring lalu dicampurkan dengan filtrat pertama. Campuran filtrat ditambah dengan aseton sampai $100 \mathrm{ml}$. Filtrat diambil $20 \mathrm{ml}$, ditambah $20 \mathrm{ml}$ air, dan diekstraksi 3 kali dengan $15 \mathrm{ml}$ etil asetat. Fraksi etil asetat dikumpulkan dan ditambah dengan etil asetat sampai $50 \mathrm{ml}$ sehingga menjadi larutan induk. Larutan blanko dibuat dari $10 \mathrm{ml}$ larutan induk ditambah larutan asam asetat glasial (5\% v/v dalam metanol sampai 25 $\mathrm{ml})$. Larutan sampel dibuat dari $10 \mathrm{ml}$ larutan induk ditambah $1 \mathrm{ml}$ larutan $\mathrm{AlCl}_{3}$ (2\% dalam larutan asam asetat glasial) dan larutan asam asetat glasial sampai $25 \mathrm{ml}$. Pengukuran dilakukan 30 menit setelah penambahan $\mathrm{AlCl}_{3}$ menggunakan Hitachi U-2800 spectrophotometer pada panjang gelombang $425 \mathrm{~nm}$ dengan pembanding kuersetin. Kuersetin adalah bagian dari keluarga flavonol yang merupakan salah satu penciri senyawa flavonoid karena banyak ditemukan pada tumbuhan (D'Andrea, 2015). Perhitungan produksi total flavonoid pada panen kedua menggunakan kadar total flavonoid panen pertama. Pengamatan senyawa bioaktif dilakukan pada sampel daun yang telah terbentuk sempurna pada daun dewasa (warna daun hijau gelap) diambil pada posisi daun ke5 (Karimuna, 2016).

\section{HASIL DAN PEMBAHASAN}

Dosis pupuk tidak berpengaruh nyata pada seluruh karakter yang diamati di panen pertama dan kedua, kecuali pada kandungan antosianin di panen kedua. Hal tersebut diduga karena sudah ada pemupukan sebelum penelitian dan pemberian pupuk guano sebagai pupuk dasar pada seluruh tanaman yang masih dapat menyediakan kebutuhan hara tanaman. Pemupukan setelah pangkas berat tidak diperlukan pada tanaman kemuning berumur 45-57 BST setelah 4-6 kali panen.

\section{Pertumbuhan Tanaman}

Hasil analisis peubah pertumbuhan bervariasi dari berbeda sangat nyata, berbeda nyata, dan tidak nyata pada perlakuan ketinggian pangkas. Pengaruh perlakuan dosis pupuk dan interaksi antara perlakuan tidak nyata terhadap peubah pertumbuhan. Diameter tajuk dan tinggi tanaman (Tabel 1), serta jumlah daun dan tunas pada cabang contoh (Tabel 2) kemuning secara umum semakin besar seiring dengan ketinggian pangkas, kecuali pada jumlah tunas pada cabang contoh setelah panen kedua.

Diameter tajuk menjadi lebih lebar karena tunas lateral dapat muncul di permukaan batang yang dominasi apikalnya terhambat. Pemangkasan di ujung tanaman akan merangsang tumbuhnya tunas lateral sehingga tajuk tanaman tumbuh melebar ke samping bukan mengerucut ke atas. Hal tersebut sesuai dengan hasil penelitian Raden (2009) pada pemangkasan batang utama jarak pagar yang dapat meningkatkan jumlah cabang primer. Tinggi tanaman akan menyesuaikan dengan tinggi pangkasannya. 
Tabel 1. Pengaruh ketinggian pangkas dan dosis pemupukan terhadap diameter tajuk dan tinggi tanaman kemuning pada panen pertama dan kedua

\begin{tabular}{|c|c|c|c|c|c|c|}
\hline \multirow{2}{*}{ Perlakuan } & \multicolumn{3}{|c|}{ Setelah Panen Pertama } & \multicolumn{3}{|c|}{ Setelah Panen Kedua } \\
\hline & $50 \mathrm{BST}$ & $51 \mathrm{BST}$ & $52 \mathrm{BST}$ & $54 \mathrm{BST}$ & $55 \mathrm{BST}$ & $56 \mathrm{BST}$ \\
\hline & \multicolumn{6}{|c|}{ Diameter Tajuk $(\mathrm{cm})$} \\
\hline \multicolumn{7}{|c|}{ Ketinggian Pangkas (cm) } \\
\hline 45 & $60.42 \mathrm{c}$ & $73.13 \mathrm{c}$ & $85.21 \mathrm{c}$ & $71.52 \mathrm{c}$ & $75.79 \mathrm{c}$ & $82.46 \mathrm{c}$ \\
\hline 60 & $90.42 \mathrm{~b}$ & $107.42 \mathrm{~b}$ & $112.71 \mathrm{~b}$ & $92.58 \mathrm{~b}$ & $101.92 \mathrm{~b}$ & $109.79 \mathrm{~b}$ \\
\hline 75 & $105.00 \mathrm{a}$ & $123.38 \mathrm{a}$ & $131.42 \mathrm{a}$ & $110.08 \mathrm{a}$ & $117.46 \mathrm{a}$ & $123.96 \mathrm{a}$ \\
\hline Uji-F & $* *$ & $* *$ & $* *$ & $* *$ & $* *$ & $* *$ \\
\hline \multicolumn{7}{|c|}{ Dosis Pupuk PA +AS $\left(\mathrm{kg} \operatorname{tanaman}^{-1} \operatorname{tahun}^{-1}\right)$} \\
\hline $0+0$ & 83.25 & 99.42 & 107.54 & 90.25 & 96.83 & 101.42 \\
\hline $7+3$ & 87.38 & 100.04 & 108.17 & 92.00 & 98.67 & 108.33 \\
\hline $14+6$ & 85.21 & 104.46 & 113.63 & 91.96 & 99.67 & 106.46 \\
\hline Uji-F & tn & tn & tn & tn & th & tn \\
\hline $\mathrm{KK}(\%)$ & 12.56 & 9.38 & 10.26 & 11.92 & 12.83 & 13.07 \\
\hline & \multicolumn{6}{|c|}{ Tinggi Tanaman $(\mathrm{cm})$} \\
\hline \multicolumn{7}{|c|}{ Ketinggian Pangkas (cm) } \\
\hline 45 & $61.33 \mathrm{c}$ & $73.67 \mathrm{c}$ & $84.38 \mathrm{c}$ & $67.45 \mathrm{c}$ & $77.63 \mathrm{c}$ & $89.88 \mathrm{c}$ \\
\hline 60 & $81.29 \mathrm{~b}$ & $96.93 \mathrm{~b}$ & $107.71 \mathrm{~b}$ & $88.04 \mathrm{~b}$ & $97.96 \mathrm{~b}$ & $111.83 \mathrm{~b}$ \\
\hline 75 & $90.08 \mathrm{a}$ & $105.38 \mathrm{a}$ & $117.08 \mathrm{a}$ & $95.33 \mathrm{a}$ & $106.38 \mathrm{a}$ & $118.58 \mathrm{a}$ \\
\hline Uji-F & $* *$ & $* *$ & $* *$ & $* *$ & $* *$ & $* *$ \\
\hline \multicolumn{7}{|c|}{ Dosis Pupuk PA +AS $\left(\mathrm{kg} \operatorname{tanaman}^{-1} \operatorname{tahun}^{-1}\right)$} \\
\hline $0+0$ & 78.88 & 92.00 & 103.42 & 84.46 & 93.96 & 105.58 \\
\hline $7+3$ & 75.58 & 88.91 & 98.92 & 83.72 & 93.54 & 106.42 \\
\hline $14+6$ & 78.25 & 94.96 & 106.83 & 82.58 & 94.46 & 108.29 \\
\hline Uji-F & $\operatorname{tn}$ & $\operatorname{tn}$ & tn & tn & tn & tn \\
\hline $\mathrm{KK}(\%)$ & 7.15 & 8.36 & 10.53 & 5.60 & 7.16 & 7.79 \\
\hline
\end{tabular}

Keterangan: BST (bulan setelah tanam). Angka yang diikuti dengan huruf yang sama pada kolom yang sama untuk masing-masing perlakuan menunjukkan pengaruh tidak nyata menurut uji DMRT $\alpha=5 \%$.

Pola pertambahan jumlah daun dan tunas pada cabang contoh diduga dipengaruhi oleh banyaknya daun dan cabang yang tidak ikut terpangkas pada tanaman (Tabel 2). Daun merupakan penghasil asimilat bagi tanaman sehingga memungkinkan untuk percepatan proses recovery dan meningkatkan pertumbuhan tanaman. Penelitian Maurin dan DesRochers (2013) memberi hasil bahwa cabang tanaman poplar dapat menjadi tempat penyimpanan hasil fotosintesis dan menjadi jalur pertukaran hara serta asimilat dari akar dan daun. Cabang tanaman kemuning pada penelitian ini merupakan tempat daun dan tunas baru muncul, sehingga dengan banyaknya jumlah cabang, luasnya permukaan cabang, dan tebalnya diameter cabang dapat menghasilkan daun atau tunas baru yang lebih banyak. Ketinggian $60 \mathrm{~cm}$ dari permukaan tanah menghasilkan jumlah daun dan tunas yang mendekati kontrol, meskipun setelah panen kedua terlihat lebih rendah tetapi tidak berbeda nyata dengan perlakuan ketinggian pangkas 45 $\mathrm{cm}$ dari permukaan tanah.

Benggul (knot) dalam istilah botani diamati terdapat pada batang tanaman yang dipangkas $75 \mathrm{~cm}$ dari permukaan tanah sehingga mengurangi produksi daun dan tunas pada cabang tanaman. Hal tersebut terlihat dari menurunnya jumlah daun di 2 dan 3 bulan setelah panen kedua jika dibandingkan dengan panen pertama sedangkan dengan ketinggian pangkas 45 dan $60 \mathrm{~cm}$ terjadi peningkatan jumlah daun di panen kedua dibandingkan panen pertama, serta pada jumlah tunas yang rendah di ketinggian pangkas $75 \mathrm{~cm}$ pada 3 bulan setelah panen kedua. Benggul yang terbentuk pada penelitian ini diduga karena pemangkasan berulang yang dilakukan di ketinggian $75 \mathrm{~cm}$ sejak tanaman berusia 30 BST sebanyak 4-6 kali panen termasuk pada penelitian ini. 
Tabel 2. Pengaruh ketinggian pangkas dan dosis pemupukan terhadap jumlah daun dan tunas pada cabang contoh tanaman kemuning pada panen pertama dan kedua

\begin{tabular}{|c|c|c|c|c|c|c|}
\hline \multirow{2}{*}{ Perlakuan } & \multicolumn{3}{|c|}{ Setelah Panen Pertama } & \multicolumn{3}{|c|}{ Setelah Panen Kedua } \\
\hline & $50 \mathrm{BST}$ & $51 \mathrm{BST}$ & $52 \mathrm{BST}$ & $54 \mathrm{BST}$ & $55 \mathrm{BST}$ & $56 \mathrm{BST}$ \\
\hline \multicolumn{7}{|c|}{ Jumlah Daun } \\
\hline \multicolumn{7}{|c|}{ Ketinggian Pangkas (cm) } \\
\hline 45 & $42.3 \mathrm{~b}$ & $103.9 \mathrm{~b}$ & $82.4 \mathrm{~b}$ & $79.4 \mathrm{~b}$ & 114.4 & 104.7 \\
\hline 60 & $54.6 \mathrm{~b}$ & $109.9 \mathrm{~b}$ & $92.8 \mathrm{~b}$ & $94.5 \mathrm{~b}$ & 120.1 & 125.9 \\
\hline 75 & $114.6 \mathrm{a}$ & $195.1 \mathrm{a}$ & 179.9 a & $125.4 \mathrm{a}$ & 158.5 & 139.5 \\
\hline Uji-F & $* *$ & $* *$ & $* *$ & $* *$ & tn & tn \\
\hline \multicolumn{7}{|c|}{ Dosis Pupuk PA + AS (kg tanaman ${ }^{-1}$ tahun $\left.^{-1}\right)$} \\
\hline $0+0$ & 71.3 & 135.5 & 122.8 & 98.4 & 130.0 & 119.3 \\
\hline $7+3$ & 66.1 & 132.3 & 119.4 & 102.7 & 140.1 & 138.4 \\
\hline $14+6$ & 74.1 & 141.1 & 112.9 & 98.1 & 122.9 & 112.4 \\
\hline Uji-F & $\operatorname{tn}$ & tn & $\operatorname{tn}$ & tn & tn & tn \\
\hline $\mathrm{KK}(\%)$ & $22.1^{\mathrm{T}}$ & $20.6^{\mathrm{T}}$ & $22.8^{\mathrm{T}}$ & $16.7^{\mathrm{T}}$ & $18.1^{\mathrm{T}}$ & $22.0^{\mathrm{T}}$ \\
\hline \multicolumn{7}{|c|}{ Jumlah Tunas } \\
\hline \multicolumn{7}{|c|}{ Ketinggian Pangkas (cm) } \\
\hline 45 & $16.3 \mathrm{~b}$ & - & $3.4 \mathrm{~b}$ & $7.8 \mathrm{ab}$ & - & 3.3 \\
\hline 60 & $19.5 \mathrm{~b}$ & - & $4.0 \mathrm{~b}$ & $6.6 \mathrm{~b}$ & - & 2.6 \\
\hline 75 & $36.2 \mathrm{a}$ & - & $7.5 \mathrm{a}$ & $13.7 \mathrm{a}$ & - & 2.0 \\
\hline Uji-F & $* *$ & - & $*$ & $*$ & - & $\operatorname{tn}$ \\
\hline \multicolumn{7}{|c|}{ Dosis Pupuk PA +AS $\left(\mathrm{kg} \operatorname{tanaman}^{-1}\right.$ tahun $\left.^{-1}\right)$} \\
\hline $0+0$ & 22.9 & - & 4.2 & 8.5 & - & 2.9 \\
\hline $7+3$ & 22.2 & - & 6.4 & 9.5 & - & 2.1 \\
\hline $14+6$ & 26.9 & - & 4.3 & 10.1 & - & 2.9 \\
\hline Uji-F & tn & - & $\operatorname{tn}$ & tn & - & $\operatorname{tn}$ \\
\hline $\mathrm{KK}(\%)$ & $19.6^{\mathrm{T}}$ & - & $28.4^{\mathrm{T}}$ & $31.1^{\mathrm{T}}$ & - & $30.4^{\mathrm{T}}$ \\
\hline
\end{tabular}

Keterangan: BST (bulan setelah tanam). Angka yang diikuti dengan huruf yang sama pada kolom yang sama untuk masing-masing perlakuan menunjukkan pengaruh tidak nyata menurut uji DMRT $\alpha=5 \% .{ }^{\mathrm{T}}=$ transformasi $\sqrt{ }(\mathrm{N}+1)$. - tidak dilakukan pengamatan.

\section{Produksi Tanaman}

Peubah produksi bervariasi dari berbeda sangat nyata, berbeda nyata, dan tidak nyata antar perlakuan ketinggian pangkas. Perlakuan dosis pupuk dan interaksi antara perlakuan tidak nyata pada seluruh peubah produksi. Bobot basah daun, bobot kering daun dan bobot basah batang meningkat seiring dengan ketinggian pangkas, kecuali pada panen pertama. Total bobot basah daun meningkat seiring dengan ketinggian pangkas. Total bobot kering pada perlakuan ketinggian pangkas $45 \mathrm{~cm}$ memberi hasil yang mendekati kontrol tetapi tidak berbeda nyata. Total bobot basah batang berbanding terbalik dengan total bobot basah daun. Perlakuan ketinggian pangkas $60 \mathrm{~cm}$ memberi hasil produksi yang mendekati kontrol pada total bobot basah daun dan batang serta bobot kering daun panen kedua (Tabel 3).

Hasil produksi panen pertama berbeda dengan panen kedua. Produksi pada panen pertama menurun seiring dengan bertambahnya ketinggian pangkas sementara pada panen kedua terjadi sebaliknya. Pada panen pertama tinggi tanaman seragam karena ada pemerataan di awal percobaan pada ketinggian $75 \mathrm{~cm}$ dari permukaan tanah, sehingga ketika dipangkas sesuai dengan perlakuan ketinggian perlakuan maka ketinggian pangkas terendah dari permukaan tanah akan memberi hasil panen terbanyak begitu pula sebaliknya. Pada panen kedua tinggi tanaman bervariasi sesuai dengan ketinggian pangkas perlakuan dan kecepatan pertumbuhan yang beragam. Batang dan daun yang tidak dipanen dapat mempengaruhi cadangan makanan dan proses fotosintesis tanaman. Semakin banyak bagian tanaman yang disisakan maka cadangan pati dan tempat fotosistesis lebih banyak sehingga biomassa yang dihasilkan tanaman dengan perlakuan ketinggian pangkas tertinggi dari permukaan tanah pun semakin tinggi. Hasil tersebut seiring dengan penelitian Delyani et al. (2017) bahwa pada panen pertama bobot basah daun dan produksi simplisia daun kumis kucing menurun seiring dengan bertambahnya ketinggian pangkas sedangkan pada panen berikutnya mulai meningkat seiring dengan ketinggian pangkas 
dengan total 6 kali panen. Pada tabel 2 terlihat jumlah daun setelah panen pertama $(50,51$, dan 52 BST) meningkat seiring dengan ketinggian pangkas, hal tersebut sesuai dengan data produksi pada panen kedua yang cenderung meningkat seiring dengan ketinggian pangkas.

\section{Kandungan Fitokimia Tanaman Kemuning Setelah Dipangkas dan Dipupuk}

Perlakuan dosis pupuk berbeda nyata pada antosianin. Perlakuan ketinggian pangkas berbeda sangat nyata pada panen kedua. Interaksi antara perlakuan ketinggian pangkas dan dosis pupuk berbeda nyata antosianin. (Tabel 4). Kadar pigmen meningkat dari panen satu ke panen dua pada setiap perlakuan percobaan.

Jumlah klorofil a yang melimpah dapat menghasilkan karbohidrat, jumlah cabang dan daun yang lebih banyak pada tanaman. Kadar klorofil a seiring dengan hasil bobot basah daun dan batang pada panen kedua. Kadar klorofil b dan karotenoid meningkat seiring dengan bertambahnya ketinggian pangkas di panen kedua. Hal tersebut diduga karena semakin tinggi pangkasan maka semakin rimbun tajuk tanaman.

Tabel 3. Pengaruh ketinggian pangkas dan dosis pemupukan terhadap produksi tanaman kemuning pada panen pertama dan kedua

\begin{tabular}{|c|c|c|c|c|c|c|c|c|c|}
\hline \multirow{3}{*}{ Perlakuan } & \multicolumn{3}{|c|}{ Bobot Basah Daun } & \multicolumn{3}{|c|}{ Bobot Kering Daun } & \multicolumn{3}{|c|}{ Bobot Basah Batang } \\
\hline & $\begin{array}{c}\text { Panen } \\
\text { pertama } \\
(49 \mathrm{BST})\end{array}$ & $\begin{array}{c}\text { Panen } \\
\text { Kedua } \\
\text { (53 BST) }\end{array}$ & $\begin{array}{l}\text { Total } \\
\text { Bobot }\end{array}$ & $\begin{array}{c}\text { Panen } \\
\text { Pertama } \\
(49 \mathrm{BST})\end{array}$ & $\begin{array}{c}\text { Panen } \\
\text { Kedua } \\
(53 \text { BST })\end{array}$ & $\begin{array}{l}\text { Total } \\
\text { Bobot }\end{array}$ & $\begin{array}{c}\text { Panen } \\
\text { Pertama } \\
\text { (49 BST) }\end{array}$ & $\begin{array}{l}\text { Panen } \\
\text { Kedua } \\
\text { (53 BST) }\end{array}$ & $\begin{array}{l}\text { Total } \\
\text { Bobot }\end{array}$ \\
\hline & \multicolumn{9}{|c|}{ 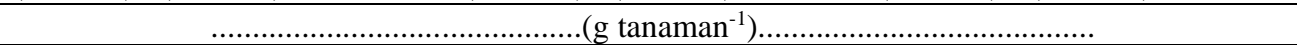 } \\
\hline \multicolumn{10}{|c|}{$\overline{\text { Ketinggian Pangkas }(\mathrm{cm})}$} \\
\hline 45 & $877.60 \mathrm{a}$ & $330.54 \mathrm{c}$ & 1208.10 & 319.83 & $126.00 \mathrm{~b}$ & 445.83 & $1402.92 \mathrm{a}$ & $221.58 \mathrm{~b}$ & $1624.50 \mathrm{a}$ \\
\hline 60 & $786.50 \mathrm{ab}$ & $537.75 \mathrm{~b}$ & 1324 & 270.58 & $168.50 \mathrm{~b}$ & 439.08 & $830.13 b$ & $364.67 \mathrm{a}$ & 119 \\
\hline 75 & $582.00 \mathrm{~b}$ & $840.08 \mathrm{a}$ & 1422.10 & 230.51 & $285.50 \mathrm{a}$ & 516.01 & $369.04 \mathrm{c}$ & $490.17 \mathrm{a}$ & $859.20 \mathrm{c}$ \\
\hline $\mathrm{Uji}-\mathrm{F}$ & * & ** & tn & tn & $* *$ & tn & $* *$ & & \\
\hline \multicolumn{10}{|c|}{ Dosis Pupuk PA + AS $\left(\mathrm{kg} \operatorname{tanaman}^{-1}\right.$ tahun $\left.^{-1}\right)$} \\
\hline $0+0$ & 723.30 & 477.92 & 1201.20 & 255.77 & 174.21 & 429.98 & 889.79 & 307.25 & 1197.00 \\
\hline $7+3$ & 742.70 & 579.96 & 1322.60 & 292.37 & 201.58 & 493.95 & 840.38 & 351.21 & 1191.60 \\
\hline $14+6$ & 780.20 & 650.50 & 1430.70 & 272.78 & 204.21 & 476.99 & 871.92 & 417.96 & 1289.90 \\
\hline Uji-F & tn & tn & tn & $\operatorname{tn}$ & tn & tn & $\operatorname{tn}$ & $\operatorname{tn}$ & tn \\
\hline KK $(\%)$ & $17.95^{\mathrm{T}}$ & $19.90^{\mathrm{T}}$ & 29.47 & $16.83^{\mathrm{T}}$ & $22.62^{\mathrm{T}}$ & 29.33 & 25.94 & $21.34^{\mathrm{T}}$ & 25.70 \\
\hline
\end{tabular}

Keterangan: BST (bulan setelah tanam). Angka-angka yang diikuti dengan huruf yang sama menunjukkan pengaruh tidak nyata menurut uji DMRT $\alpha=5 \%$. ${ }^{\mathrm{T}}$ transformasi $\sqrt{ }(\mathrm{N}+0.5)$.

Tabel 4. Pengaruh perlakuan ketinggian pangkas dan pemupukan terhadap pigmen tanaman kemuning pada panen pertama dan kedua

\begin{tabular}{|c|c|c|c|c|c|c|c|c|}
\hline \multirow{3}{*}{ Perlakuan } & \multicolumn{2}{|c|}{ Klorofil a } & \multicolumn{2}{|c|}{ Klorofil b } & \multicolumn{2}{|c|}{ Antosianin } & \multicolumn{2}{|c|}{ Karotenoid } \\
\hline & $\begin{array}{l}\text { Panen } \\
\text { Pertama }\end{array}$ & $\begin{array}{l}\text { Panen } \\
\text { Kedua }\end{array}$ & $\begin{array}{l}\text { Panen } \\
\text { Pertama }\end{array}$ & $\begin{array}{l}\text { Panen } \\
\text { Kedua }\end{array}$ & $\begin{array}{l}\text { Panen } \\
\text { Pertama }\end{array}$ & $\begin{array}{l}\text { Panen } \\
\text { Kedua }\end{array}$ & $\begin{array}{l}\text { Panen } \\
\text { Pertama }\end{array}$ & $\begin{array}{l}\text { Panen } \\
\text { Kedua }\end{array}$ \\
\hline & & & & $\ldots . .(\mathrm{m}$ & $\left.{ }^{-1} \mathrm{BB}\right) .$. & ….......... & ……. & $\ldots \ldots \ldots$ \\
\hline \multicolumn{9}{|c|}{ Ketinggian Pangkas (cm) } \\
\hline 45 & $0.75 \mathrm{a}$ & $1.05 b$ & 0.29 & $0.43 b$ & 0.004 & $0.011 \mathrm{a}$ & 0.03 & $0.05 b$ \\
\hline 60 & $0.76 \mathrm{a}$ & $1.29 \mathrm{a}$ & 0.30 & $0.55 \mathrm{a}$ & 0.004 & $0.009 b$ & 0.03 & $0.07 \mathrm{a}$ \\
\hline 75 & 0.72 & $1.41 \mathrm{a}$ & 0.33 & $0.57 \mathrm{a}$ & 0.005 & $0.009 b$ & 0.03 & $0.07 \mathrm{a}$ \\
\hline Uji-F & $\operatorname{tn}$ & $* *$ & tn & $* *$ & tn & $* *$ & $\operatorname{tn}$ & $* *$ \\
\hline \multicolumn{9}{|c|}{$\begin{array}{l}\text { Dosis Pupuk PA + AS } \\
\left(\mathrm{kg} \operatorname{tanaman}^{-1} \text { tahun }^{-1}\right)\end{array}$} \\
\hline $0+0$ & $0.73 \mathrm{a}$ & 1.23 & 0.29 & 0.52 & 0.004 & $0.011 \mathrm{a}$ & 0.03 & 0.06 \\
\hline $7+3$ & $0.75 \mathrm{a}$ & 1.19 & 0.29 & 0.49 & 0.004 & $0.009 b$ & 0.03 & 0.05 \\
\hline $14+6$ & 0.75 & 1.32 & 0.35 & 0.55 & 0.004 & $0.008 b$ & 0.03 & 0.07 \\
\hline $\mathrm{Uji}-\mathrm{F}$ & tn & tn & tn & tn & tn & $*$ & tn & tn \\
\hline Interaksi & tn & tn & tn & tn & tn & $*$ & tn & tn \\
\hline KK $(\%)$ & 19.95 & 15.43 & 24.05 & 18.07 & $0.12^{\mathrm{T}}$ & 22.51 & $0.99^{\mathrm{T}}$ & 28.43 \\
\hline
\end{tabular}

Keterangan: Angka-angka yang diikuti dengan huruf yang sama menunjukkan pengaruh tidak nyata menurut uji DMRT $\alpha=5 \%$.). ${ }^{\mathrm{T}}$ transformasi $\sqrt{ }(\mathrm{N}+0.5)$. 
Menurut Setyanti et al. (2013) daun yang rimbun menghasilkan klorofil yang melimpah. Kondisi tersebut juga dapat menyebabkan daun bawah ternaungi oleh daun di atasnya sehingga membutuhkan tambahan pigmen untuk menangkap cahaya. Penelitian Soverda (2011) membuktikan bahwa daun kedelai baik varietas toleran maupun peka terhadap naungan memiliki kadar karotenoid yang lebih tinggi dengan pemberian naungan $50 \%$ dibandingkan dengan tanpa naungan. Perlakuan ketinggian pangkas 60 cm dari permukaan tanah menghasilkan klorofil a, klorofil b, dan karotenoid yang mendekati kontrol.

Perlakuan ketinggian pangkas $45 \mathrm{~cm}$ menghasilkan kadar antosianin tertinggi di panen kedua (Tabel 4). Hal tersebut diduga karena cekaman abiotik berupa pemangkasan dan paparan cahaya matahari berlebih dapat meningkatkan kadar antosianin. Hasil tersebut sejalan dengan penelitian Susanti et al. (2011) yang menyatakan bahwa pemanenan yang intensif terhadap kolesom dapat meningkatkan kadar antosianin.

Pemberian pupuk di panen kedua menurunkan kadar antosianin (Tabel 4). Hal ini diduga karena metabolit sekunder terinduksi akibat cekaman kahat hara pada tanaman sehingga tanaman mengaktifkan sistem pertahanan dengan memproduksi senyawa flavonoid dalam bentuk antosianin di daun. Hasil serupa didapatkan dari penelitian Tripatmasari et al. (2014) bahwa kandungan antosianin pada daun dewa Gynura pseudochina (L) DC tertinggi terdapat pada perlakuan tanpa pemupukan.

Antosianin tertinggi pada panen kedua dihasilkan dari interaksi antar perlakuan ketinggian pangkas $45 \mathrm{~cm}$ dan dosis pupuk $0 \mathrm{~kg}$ PA + $0 \mathrm{~kg}$ AS dengan nilai persentase $66.67 \%$ lebih tinggi daripada perlakuan kontrol (Tabel 5). Hal tersebut diduga akibat cekaman abiotik pemangkasan dan kahat hara yang menginduksi peningatan produksi antosianin sebagai sistem pertahanan tanaman.

Bobot kering daun mempengaruhi produksi total flavonoid pada penelitian ini karena kadar total flavonoid hanya diukur satu kali di awal penelitian. Jumlah produksi total flavonoid panen pertama dan kedua pada ketinggin pangkas $60 \mathrm{~cm}$ dari permukaan tanah dan dosis pupuk 14 $\mathrm{kg}$ PA $+6 \mathrm{~kg}$ AS dapat mendekati produksi total flavonoid kontrol meskipun tidak nyata.

Tabel 5. Interaksi pengaruh perlakuan ketinggian pangkas dan dosis pupuk terhadap antosianin pada panen kedua

\begin{tabular}{|c|c|c|c|c|}
\hline \multirow[b]{2}{*}{ Ketinggian Pangkas } & \multicolumn{3}{|c|}{ Dosis Pupuk (kg tanaman $\left.{ }^{-1} \operatorname{tahun}^{-1}\right)$} & \multirow[b]{2}{*}{ Rataan } \\
\hline & $0+0$ & $7+3$ & $14+6$ & \\
\hline \multicolumn{5}{|c|}{ 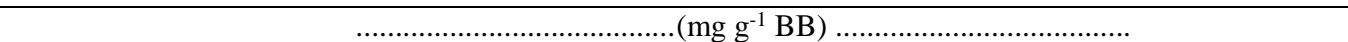 } \\
\hline 45 & $0.015 \mathrm{a}$ & $0.010 \mathrm{~b}$ & $0.009 b$ & $0.011 \mathrm{a}$ \\
\hline 60 & $0.010 \mathrm{~b}$ & $0.009 b$ & $0.009 b$ & $0.009 b$ \\
\hline 75 & $0.009 b$ & $0.008 b$ & $0.009 \mathrm{~b}$ & $0.009 \mathrm{~b}$ \\
\hline Rataan & $0.011 \mathrm{a}$ & $0.009 \mathrm{~b}$ & $0.009 b$ & 0.029 \\
\hline Uji F & & & & * \\
\hline $\mathrm{KK}(\%)$ & & & & 22.51 \\
\hline
\end{tabular}

Keterangan: Angka-angka yang diikuti dengan huruf yang sama menunjukkan pengaruh tidak nyata menurut uji DMRT $\alpha=5 \%$.).

Tabel 6. Pengaruh ketinggian pangkas dan dosis pemupukan produksi total flavonoid tanaman kemuning pada panen pertama dan kedua

\begin{tabular}{|c|c|c|}
\hline \multirow{2}{*}{ Perlakuan } & Panen pertama & Panen kedua \\
\hline & \multicolumn{2}{|c|}{$\left(\mathrm{g} \operatorname{tanaman}^{-1}\right)$} \\
\hline \multicolumn{3}{|c|}{ Ketinggian Pangkas (cm) } \\
\hline 45 & 1.25 & 0.47 \\
\hline 60 & 1.08 & 0.78 \\
\hline 75 & 0.87 & 0.99 \\
\hline Uji-F & tn & tn \\
\hline \multicolumn{3}{|c|}{ Dosis Pupuk PA +AS (kg tanaman ${ }^{-1}$ tahun $\left.^{-1}\right)$} \\
\hline $0+0$ & 1.14 & 0.82 \\
\hline $7+3$ & 0.97 & 0.62 \\
\hline $14+6$ & 1.09 & 0.81 \\
\hline Uji-F & $\operatorname{tn}$ & tn \\
\hline $\mathrm{KK}(\%)$ & $21.71^{\mathrm{T}}$ & $16.60^{\mathrm{T}}$ \\
\hline
\end{tabular}

Keterangan: Angka-angka yang diikuti dengan huruf yang sama menunjukkan pengaruh tidak nyata menurut uji DMRT $\alpha=5 \% .{ }^{\mathrm{T}}$ transformasi $\sqrt{ }(\mathrm{N}+0.5)$. 


\section{KESIMPULAN}

Perlakuan ketinggian pangkas $60 \mathrm{~cm}$ dari permukaan tanah merupakan pemangkasan berat terbaik untuk pertumbuhan, produksi, dan produksi total flavonoid tanaman kemuning yang berumur 45-57 BST setelah 4-6 kali panen, sehingga diharapkan dapat mengatasi benggul selama 2 kali periode panen. Pemupukan tidak memberikan hasil yang berbeda nyata sehingga tidak perlu diberikan pada tanaman kemuning berumur 45-57 BST setelah 4-6 kali panen.

\section{DAFTAR PUSTAKA}

D’Andrea, G. 2015. Quercetin: a flavonol with multifaceted therapeutic applications? Fitoterapia. 106(32): 256-271.

Delyani, R., A. Kurniawati, M. Melati, D.N. Faridah. 2017. Produksi simplisia kumis kucing dengan perbedaan cara pemupukan dan ketinggian pangkas pada rotasi panen tiga minggu. J. Hort. Indonesia. 8(3): 209-217.

Hayanti, E.D., Yuliani, H. Fitrihidayati. 2014. Penggunaan kompos kotoran kelelawar (guano) untuk meningkatkan pertumbuhan tanaman kacang tanah (Arachis hypogaea). LenteraBio. 3(1): 711.

Kardono L.B.S., N. Artanti, I.D. Dewiyanti, T. Basuki. 2003. Selected Indonesian Medicinal Plants: Monographs and Descriptions. Grasindo, Jakarta.

Karimuna, S.R., S.A. Aziz, M. Melati. 2015 Correlations between leaf nutrient content and production of metabolites in orange jessamine (Murraya paniculata $\mathrm{L}$. Jack) fertilized with chicken manure. Journal of Tropical Crop Science. 2(1): 16-25.

Lisboa, M., E. Acuna, J. Cancino, F. Chao, F. Munoz, R. Rodriguez, P. Volker. 2014. Physiological response to pruning severity in Eucalyptus regnans plantations. New Forests. 45(6): 753764.
Mattjik, N.A. 2010. Tanaman Hias dan Bunga Potong. IPB Press, Bogor.

Maurin, V., A. DesRochers. 2013. Physiological and growth responses to pruning season and intensity of hybrid poplar. Forest Ecology and Management. 304: 399-406.

Ng, M.K., Y. Noaman-Abdulhadi, Y.K. Chea, S.K. Yeap, N.B. Alitheen. 2012. Bioactivity studies and chemical constituents of Murraya paniculata (Linn) Jack. International Food research Journal. 19(4): 1307-1312.

[PPTK] Pusat Penelitian Teh dan Kina. 2006. Petunjuk Kultur Teknis Tanaman Teh Edisi ke-3. Lembaga Riset Perkebunan Indonesia, Pusat Teh dan Kina Gambung. Bandung.

Raden, I., B.S. Purwoko, Hariyadi, M. Ghulamahdi, E. Santoso. 2009. Pengaruh tinggi pangkasan batang utama dan jumlah cabang primer yang dipelihara terhadap produksi minyak jarak pagar (Jatropha curcas L.). J. Agron. Indonesia 37: 159-166.

Respatie, D.W. 2007. Pengaruh tinggi pangkasan dan pemupukan $\mathrm{N}$ terhadap pertumbuhan dan produksi kandungan bahan bioaktif dan jambu biji. Tesis. Institut Pertanian Bogor. Bogor. 52 hal.

Setyanti, Y.H., S. Anwar, W. Slamet. 2013. Karakteristik fotosintetik dan serapan fosfor hijauan alfalfa (Medicago sativa) pada tinggi pemotongan dan pemupukan nitrogen yang berbeda. Animal Agriculture Journal. 2(1): 86-96.

Soverda, N. 2011. Studi karakteristik fotosintetik tanman kedelai toleran terhadap naungan. Jurnal Ilmu Pertanian KULTIVAR. 5(1): 41-52.

Susanti, H., S.A. Aziz, M. Melati, S. Susanto. 2011. Protein and anthocyanin production of waterleaf shoots (Talinum triangulare (Jacq.) Willd) at different levels of nitrogen+potassium and harvest intervals. J. Agron. Indonesia. 39(2): 119-123. 
Syahadat, R.M., S.A. Aziz. 2012. Pengaruh komposisi media dan fertigasi pupuk organik terhadap kandungan bioaktif daun tanaman kemuning (Murraya paniculata (L.) Jack) di pembibitan. Buletin Littro. 23(2):142-147.

Taufika, R., S.A. Aziz, M. Melati. 2016. Produksi flavonoid daun kemuning (Murraya paniculata 1. Jack) pada dosis pupuk organik dan interval panen yang berbeda. Bul. Littro. 27(1): 27-36.

Tripatmasari, M., S.A. Aziz, M. Ghulamahdi. 2014. Pengaruh pemupukan dan waktu pemanenan terhadap produksi antosianin daun dan kuisertin umbi tanaman daun dewa (Gynura pseudochina (L.) DC). AGROVIGOR. 7(1): 25-35.

Utami, N. 2015. Produksi dan flavonoid daun kemuning (Murraya paniculata L. Jack) dengan perbedaan interval dan tinggi panen serta dosis pupuk organik. Tesis. Institut Pertanian Bogor. Bogor.

Zulkarnain H. 2009. Dasar-dasar Hortikultura. PT Bumi Aksara, Jakarta. 